\title{
Between the Time of Physics and the Time of Metaphysics, the Time of Tense Logic?
}

\section{Sosein, Dasein, Zeitsein}

\section{Abstract}

According to Russell, Being is divided into atemporal universals and temporal particulars. But, to the extent that the Antisthene's caballeity pops up in the topos noeton, the ancestors of the horse must precede the horse in the sublunar. Thus, Being must be divided into Sosein, Dasein and Zeitsein. Only the Whiteheadian "eternal objects", such as geometrical forms and colours, are atemporal universals, while caballeity is in the Zeitsein together with Conquérant (one among Napoleon's horses). In this ontology, according to the Lautmanian shift, Spatiotemporality pertains to the Sosein and has a two-fold structure: logical and mathematical. The tense logic of A.N. Prior describes it, while its link with the mathematics of spacetime is fixed by the Boolean kernel in the von Neumann algebra for quantum logic. This speculation will be preceded by a narrative exposition of elementary tense logic.

* I am grateful to the all staff at the What is time? symposium for their invitation and generous hospitality. Great thanks are especially due to Rocco Ronchi for his marked concerns, to Elie During for the courtesy of his discussion and to Alessandra Campo for the truth of her philosophical enthusiasm. A special thanks is for the anonymous reviewer of this paper.

\section{The Tale of Tense Logic}

Tense logic is a variety of temporal logic, and temporal logic is a branch of modal logic. Thus, in order to give a short history of tense logic, we must start by tracing a short genealogy of the modal logic. ${ }^{1}$ The latter has three main moments: the Leibnizian foundation, the Kripkean mathematization and the creation of tense logic by Arthur Prior.

1 See Blackburn, De Rijke and Venema (2001). Arthur Prior and Hybrid Logic is a fascinating paper which focuses on the more promising lines of thought in the area. 


\subsection{The Leibnizian Foundation}

In a draft ${ }^{2}$ written in 1671 or 1672, Leibniz discloses, in Russellian terms, the structural similarity between three versions of the Apulean square AEIO. This is the Leibnizian Table of Apulean squares:

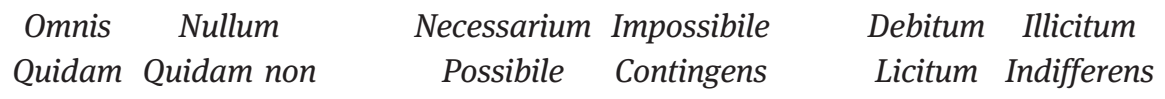

In symbols (or in English, where symbols are still missing):
$\forall \neg \exists$
$\square p \neg \diamond p$
Obligatory Forbidden
$\exists \neg \forall$
$\diamond p \neg \square p$
Permitted Optional

This table of similarities has two main consequences. The first is the well-known thesis that a necessary truth is true in all possible worlds. ${ }^{3}$ In symbols:

$$
\square p \Leftrightarrow \forall w \mid-{ }_{w} p
$$

("Necessarily $p$ iff for each world $w$ it is true at $w$ that $p$ ")

This Leibnizian analysis of necessity (generalizable to the other modes of the square) is of such significance that it deserves a name. I will call it Leibniz's Bridge. It is a bridge because it connects a left-side modality with a right-side quantifier. In Carnapian terms, modality is the explanandum and quantification is the explanans. Of course, the quantifier operates in the possible worlds of Molina, dubious entities surrounded by a metaphysical flavour. However, in the view of such logicians as Carnap, quantification theory enjoys a less controversial status than modal logic.

2 It was rediscovered by Blanché when he prefaced the Etudes de logique déontique of Kalinowski. Gardies relates : "Il a en effet trouvé les textes en question grâce à M. Serres qui dans $L e$ système de Leibniz et ses modèles mathématiques cite L. Couturat, lequel résume Definitio justitiae universalis, c'est-à-dire le fragment N. $12_{6}$ des Elementa juris naturalis de l'édition de l'Académie Prussienne des Sciences... publié pour la première fois par A. Trendelenburg dans ses Historische Beiträge zur Philosophie" (Gardies 1974, 265-275).

3 On the Leibnizian source of this theme, see Kalinowski (1985, 236-237) who refers to another text, edited by Couturat in the Opuscules et fragments inédits of Leibniz (1903): Phil. IV, 3, a, 1-4, sans titre, pp. $16-24$. 
The second consequence of the Leibnizian reformulation of Apuleio's square is a generalisation of the concept of modality itself. According to Leibniz, beside the metaphysical modalities of possibility and necessity-which are well-known since Aristotle-there are also deontic modalities such as duty and rightness. And so, we can say that his generalisation systematizes philosophy with modal logic. Its Begriffsschrift is the standard symbolism of the latter: on the Apulean square, $\square$ and $\diamond$ are transposed in their ethereal versions [ ] ("Box") and \langle\rangle ("Diamond"), so that the subalternation obtained is:

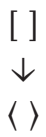

It may be rephrased as: "the diamond is in the box".

\subsection{The Kripkean Mathematization}

With respect to modal logic, we must distinguish between its axiomatization and its mathematization. The well-known axiomatization of modal logic was laid down in its main lines by C.I. Lewis in 1932 (Lewis and Langford 1932). But the mathematization of modal logic is another story. This concept was introduced by Robert Goldblatt (2005) and the understanding of its true meaning requires a philosophical elucidation.

The mathematization of modal logic has at least two births. The first, as we shall see, is probably due to Arthur Prior. The second, instead, is due to Saul Kripke, ${ }^{4}$ the philosopher who provided its canonical formulation. The cornerstone of the latter is a Kripke-model or K-model. A Kripke-model M must be written in two main versions. The original (Kripke 1963) ${ }^{5}$ one is:

$$
\mathrm{M}=\langle\langle W, P\rangle, \mathrm{V}\rangle
$$

\footnotetext{
4 Here we cannot discuss the question of priority between authors. In addition to the already mentioned paper by Goldblatt on the evolution of mathematical modal logic, see Copeland (2002). And it is enough to say that the mathematizations of Prior and Kripke are independent from each other. The publication of the results of the young Kripke's work has been postponed because of bad advices from his academic masters.

5 Original version but not in literal terms. The essential point is the difference between this original version, with its philosophical significance, and the new one which has vanished in the rarefied air of abstract formalism.
} 
In this version of the model $\mathrm{M}, W$ is a set of possible worlds $w, P$ is the relation of relative possibility between possible worlds, and $\mathrm{V}$ is the so-called "function of valuation" which takes the proposition $p$ of a language $\mathrm{L}$ as argument and the subsets of $W$ where $p$ is true as values.

From a theoretical point of view, in Kripke's model the two members have a very different status (Blackburn, De Rijke and Venema 2001, Df 1.19, 17). The couple $\langle W, P\rangle$, i.e., the frame of the model, gives the mathematical picture of its ontology, while the valuation function $\mathrm{V}$ gives the additional information endowing this ontology with a logic. In Husserlian terms, which are derived from Aristotle, one can say that the frame is the Ontology of the model and the valuation is its Apophantics. In the frame, usually, there is no relation of "relative possibility", but a relation of accessibility. This, at least, is what Peter Geach suggested to Prior in a letter of 1960. Yet, relative possibility and accessibility are the converse of one another: $w$ has access to $w$ ' if and only if $w$ ' is possible relatively to $w$.

Therefore, since modal logic has evolved, we may write Kripke's model in the following terms:

$$
\mathrm{M}=\langle\langle E, R\rangle, \mathrm{V}\rangle
$$

In this new version $E$ is any non-empty set, whose members are not only the old "worlds" of Molina or Leibniz, but as well "points", instants, words, or whatnot; and $R$ is any binary relation. This acceptation defines an abstract or "formal" Kripke model.

Now, when modal logic is endowed with a Kripke model, what is the effect of this model on those concepts of modal logic illustrated by the definition of necessity that we find in Leibniz? The definition of necessity becomes

$$
\mathrm{M}\left|-{ }_{v} \square p \Leftrightarrow \forall w w P v \rightarrow \mathrm{M}\right|{ }_{-}{ }_{w} p
$$

("In $\mathrm{M}$ it is true at $v$ that necessarily $p$ iff for all $w$, if $w$ is possible relatively to $v$, then in $M$ it is true at $w$ that $p$ ")

In other words, a footbridge is added on the right side of Leibniz's bridge. It conditions or controls the relevance of possible worlds in the definition of a modality as a constraint imposed on relative possibility, so that the relation $R$ of an abstract model can be said to be a relation of "parametrization".

Now, why is this footbridge or parametrization a mathematization of modal logic? A crucial example will help us to answer this question. Yet, in order to find it, we have to return to the second modal discovery made by Leibniz, i.e., the structural similarity between the metaphysical modalities, such as possibility and necessity, on the one hand, and the deontic modalities, such as permission 
and obligation, on the other. Nevertheless, this structural similarity does not go without restrictions.

Indeed, when the Apulean square is decorated with metaphysical modalities, we find in its A-I side, that is between the necessity $\square p$ and the possibility $\diamond p$, the halfway house of the naked $p$ :

This writing presupposes the law $\square p \rightarrow p$ (a necesse ad esse valet consequentia) according to which, if Cicero is necessarily Tullius Marcus, then Cicero is Tullius Marcus. But if we resort to deontic modalities, things change. From the fact that Babbitt has the duty to pay taxes, it doesn't follow that Babbitt pays taxes, because metaphysical and normative modalities have a different meaning. But this fact has also a mathematical accompaniment. If the relation of parametrization $P$ or $R$ is compelled to be reflexive, then we have $w P w$ and so, by applying our previous definition of necessity, we now obtain

$$
1-{ }_{v} \square p \Rightarrow \mid-{ }_{v} p
$$

("If it is true at $v$ that necessarily $p$, then it is true at $v$ that $p$ ")

Nonetheless, there is no corresponding principle for the deontic modalities.

Now, reflexivity, as well as transitivity, symmetry (etc.) are mathematical features of a relation. So that, if one controls the modal laws using these mathematical attributes of the parametrizing relation $R$, modal logic becomes mathematical modal logic in the sense of Goldblatt.

\subsection{The Creation of Tense Logic by Arthur Prior}

Arthur Norman Prior was the main founder of temporal logic and the creator of tense logic. Overall, its work can be broken down into three major momentsmovements: 1. an anachronistic encounter between Diodorus Chronos and St. Thomas Aquinas; 2. a mathematization of temporal logic and 3. the encoding of tense logic. 


\subsubsection{St. Thomas Aquinas Meets Diodorus Chronos}

The foundation of temporal logic coincides with the erection of an Apulean column containing a pedestal (I) and a capital (A). Prior founds the pedestal I of temporal logic in Aquinas definition of past and future: the Thomas Aquinas Theorem of temporal logic:

Past is what has been present and future is what will be present (Est enim praeteritum quod fuit praesens, futurum autem quod erit praesens)

More profoundly this definition means that the present appears in the three "parts" of time: in the past as past present, in the present as present and in the future as future present. As a result of this, only two symbols will be required on the pedestal position I: $P p$ for "It is past that $p$ " and $F p$ for "It is future that $p$ "; for the present time, the simple $p$ will be enough, since its illustrations will be, for example, "It rains" in order to report a present fact equally reported in the $p$ of $P p$ and $F p$ according to the Thomas Aquinas theorem.

Here a remark is imperative. If a census of the symbols is taken as the criterion for a census of the modalities, then each post on the Apulean column will require, in temporal logic, two modalities, such as $P p$ and $F p$. The capital A of temporal logic has been designed by taking a definition of necessity given by Diodorus Chronos and remedying its hemiplegia.

Thanks to Boethius we know the four definitions of the four modalities given by Diodorus Chronos. Each one fits with a position of the Apulean square AEIO. But before Prior's work, faced with these Diodorean definitions, the historians of logic were comme une poule qui a trouvé un couteau. Among these definitions, in fact, we find for example this definition of necessity:

Necessary is what, being true, will not be false.

If we put this Diodorean definition of necessity at the top A of our AI column, what we obtain as capital of the column is only a half-Janus which, camped in the present, can only see the future. And all Diodorean modalities are affected by this semi-blindness. Yet, from Prior's point of view, this means that Diodorus has provided only one half of the couple required in position A. Thus, the Diodorean capital must be completed with the Aquinate pedestal in order to obtain on its top a well-balanced Janus-logic. The required symbols are $H p$ and $G p$, with the mnemonics "it always Has been the case" and "it is always Going to be the case"; in French: Auparavant et Dorénavant.

When all this is done, we get the complete Column of Temporal Logic, with its Aquinate pedestal and its Diodorean capital:

Hp $\mathrm{p}$ Gp

Auparavant $\mathrm{p} p$ Dorénavant $\mathrm{p}$ 


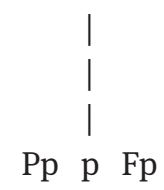

One of the laws of this logic is $P p \rightarrow G P p$ ("Whatever has happened will always have happened").

\subsubsection{The Mathematization of Temporal Logic}

On $27^{\text {th }}$ August 1954, in his Presidential Address at the second New Zealand Congress of Philosophy (held in Wellington) Prior unveiled a calculus which, in its published version of 1958, contains the following formula:

$$
1-{ }_{t} G p \Leftrightarrow \forall u\left(t<u \rightarrow \mid-{ }_{u} p\right)
$$

("It is true at $t$ that dorénavant $p$ iff for all $u$, if $t$ is followed by $u$, then it is true at $u$ that $p$ ")

Since in this formula the truth of $p$ at $u$ is conditioned by the relation of succession $(<)$ between $t$ and $u$, thanks to it Prior accomplished the mathematization of both temporal and modal logic. In other words, building a Prior's bridge for temporal logic as a case of the Leibnizian bridge built for modal logic, Prior adds on the right side of the latter the footbridge of the "before-after relation" in its function of parametrization.

As an illustration of this function, let's take the formula $F p \rightarrow F F p$. Is it a law of temporal logic? Yes, if, generally, $t<u \rightarrow \exists v(t<v \& v<u)$.

Now this condition of density can be presented either as an attribute of the parametrizing relation $(<)$, or as an attribute of the set on which this relation plays (here it is a set of temporal moments). This shows that, in a Kripke model $\langle\langle E, R\rangle, \mathrm{V}\rangle$, the frame $\langle E, R\rangle$ which is denoting the ontology of the model, enjoys a strong unity because the mathematical attribute (such as density), that is the reason of its inclusion in the alleged model, can be attributed either to $E$ or to $R$.

\subsubsection{The Emergence of Tense Logic}

Among Prior's bridges, let's now consider the following one:

$$
1-{ }_{t} P p \Leftrightarrow \exists u\left(u<t \& \mid-{ }_{u} p\right)
$$


("It is true at $t$ that $p$ is past iff there is a $u$ which precedes $t$ and it is true at $u$ that $p$ ")

Here we must remember that, according to McTaggart (1908), any event $E$ can be grasped in two series: it can be said to be future, present and past-the three attributes of the A-series-and it can be temporally related with other events with respect to which it can be said to come before, be contemporary with or come after - the three relations of the B-series. Now, as we can see if we consider, for example, the succession of births of Homer, Milton and Borges, there is no change in the B-series but only in the A-series. Only in the latter, in fact, is a future event present and then becomes past. Then, McTaggart's distinction decides the fate of the metaphysics of time: if the B-relations prevail, we are in the timeless world of Parmenides, Spinoza and Bradley; if the A attributes prevail, we live in the moving world of Heraclitus, Leibniz, Bergson, Alexander, Whitehead or Prior.

Prior thematized this metaphysical watershed in his temporal logic. In the last equivalence, in fact, we find that, on the left side, the A attribute $P$ of McTaggart has become a modal one, and that, on the right side, the B relation < of McTaggart has become a parametrizing relation of mathematical modal logic. So, we are no more in the situation of the Kripkean models $\langle\langle E, R\rangle, \mathrm{V}\rangle$ where any binary relation $R$ was doing the job of the parametrizing one. In the temporal logic of Prior, in other words, not only must " $>$ " have its ordering meaning, but this relational meaning has the same philosophical and metaphysical relevance given to it by McTaggart.

Arthur Prior is the logician who has introduced the metaphysics of time into temporal logic. But this contamination is only the first step of his revolution. In fact, from Leibniz to Carnap (and his followers), Leibniz's bridge has been conceived as a path connecting left-shore modalities with right-shore quantifications. Yet, if we follow Prior, Leibniz's bridge becomes a palindrome that can be crossed in both directions, with different results. If we go from the A attributes on the left shore to the B relations on the right shore, we are in temporal logic. But if we go from the $B$ relations to the $A$ attributes as modalities, we enter into (pure) tense logic. ${ }^{6}$

6 See Dumoncel (2018). 


\section{The Pythagorean Table of Physics}

Physics has its Pythagorean table ${ }^{7}$ (Table T):

$\begin{array}{cc} & \text { Space-time } \\ \text { c } & \text { Space, Time and Matter } \\ \text { h } & \text { Mechanical Action : } \\ & \mathrm{mv} \times \mathrm{d} \mathrm{mv}^{2} \times \mathrm{t}\end{array}$

This table represents space-time in its two main physical forms. It is a doubleentry table where the abscissa opens to the general notion of space-time and the ordinate superposes both a $c$ and an $h$ line. Of course, the letters $c$ and $h$ refer to Relativity and Quantum Mechanics: $c$ is Einstein's constant and $h$ is the Planck constant. In short, this Pythagorean table shows that the $20^{\text {th }}$ century's revolutionary physics is fully spatio-temporal or, more exactly, doubly spatiotemporal: there is a relativistic spatio-temporality and a quantum spatio-temporality. The first is notorious; the second needs to be made explicit. What is quantized in Quantum Mechanics is, in fact, the mechanical action and the mechanical action can be expressed in both a spatial and a temporal form. Thus, a quantized action is a link between time and space: a fact which is quite ironical with respect to the history of the development of physics.

Leibniz, as it is well-known, has made of continuity one of the most important principles of nature (Natura non facit saltus) and something like a quantized action, precisely to the extent that it is a discrete action, seems to refute this principle. Yet, Leibniz is also the philosopher-physicist who saw mechanical action (the so-called "moving-action") as the heart of physics. This fact is duly registered by Martial Gueroult in his Leibniz. Dynamique et Métaphysique (1934). Here, Gueroult has also argued that Leibniz was aware of the spatio-temporal character of mechanical action. What he called "action mortice", in fact, is "the product of the amount of movement multiplied by the space travelled or of the living force multiplied by time” (Gueroult, 1967, 50, our translation). So that, for the momentum and the energy, the best Begriffsschrift is the Leibnizian couple $\left\langle m v, m v^{2}\right\rangle$.

Now, let us consider Heisenberg's relations ${ }^{8}$ of indeterminacy transliterated in this Leibnizian Begriffsschrift:

7 I have presented a first version of this thesis when I was invited by Elie During to give a lecture in his seminar series on physics and philosophy at Diderot University.

8 Where $d$ shortens "distance" as a coordinate of space. 
(H1) $\Delta m v \times \Delta d \geq h$

(H2) $\Delta m v^{2} \times \Delta t \geq h$

These relations can be viewed as a simple corollary of our Pythagorean table: $\mathrm{H} 1$ stating the spatial Heisenberg relation, $\mathrm{H} 2$ its temporal mate. But this fact can also work as the occasion for a reflection: which account does Heisenberg give for the two members in each relation? What is common to $d$ and $t$ on the one hand and to $m v$ and $m v^{2}$ on the other? In brief, what is the ratio essendi of the spatial or temporal factor on the one side, and of the energy or momentum factor on the other?

With regard to this issue, Leibniz provides, if not the concepts, at least the vocabulary. As Gueroult explains: "If extension is considered in time, intensity is force; if it is considered in space, intensity is speed"' (Gueroult, 1967, 130, our translation). Here we have the Leibnizian watershed of Nature: in Nature, space and time are the extensive components; momentum and energy are the intensive ones.

This Leibnizian vocabulary will receive its full conceptual expression when it will be housed in Lautman's philosophy of science (Dumoncel 2008) and in its systematic and speculative network. Lautman, in fact, is a direct heir of Plato and it is well known that Plato, trying to give a blueprint of his allegory of the Cave, traced an analogical Line between the visible and the intelligible worlds which undergoes a second analogical division. Thus, the scale of beings or realms we obtained has the following four steps:

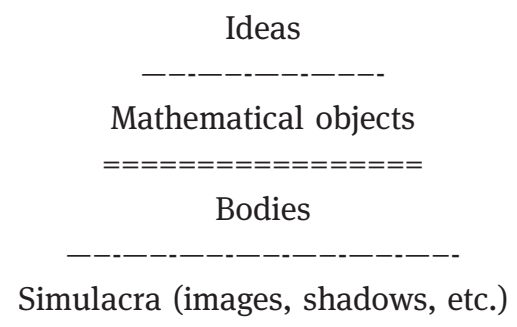

By means of Lautmanian transposition, we obtain the Lautman scale:

Ideas

9 Here, in $m v$, since the mass $m$ is constant, the velocity $v$ suffices to represent $m v$ as a variable factor. 


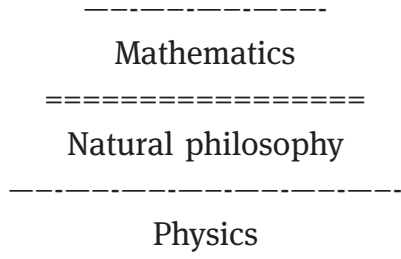

From a philosophical point of view, we find that, on the Lautman Line, the mathematical and the physical floors are already given and defined by their wellknown scientific status. What is problematic are the floor of the "Ideas" and the floor of Natural philosophy. The former overcomes what concerns our presen $t^{10}$ but the latter, according to Lautman, plays a crucial role in our theory of time. In the Lautman scale, Natural philosophy works in fact as a lock between Mathematics and its application in Physics. And it is here that the Leibnizian watershed of Nature plays a key-role: we leave $m v$ and $m v^{2}$, as well as energy and momentum, to the physicist, keeping for the philosopher only the Leibnizian couple of extensive and intensive. This is the Lautmanian sampling of Natural Philosophy.

\section{The Zeitsein in its Diagram}

From Plato to Russell, passing through Leibniz, metaphysics has been crudely dualist. In the exsanguinous language of Russell, metaphysics boils down to the $\varphi x$ and the $a$ to be substituted to the $x$ in $\varphi x$. So, in the vocabulary of Nicolaï Hartmann, Being is split in the Sosein of the "universals" $\varphi x$ and the Dasein of the "particulars" $a$. Yet, symbolic logic has been constructed by mathematicians, and in mathematics the typical $a$ is a number, again in the Sosein. Conversely, the Sosein is supposed to include the caballeity.

Darwin has changed all this. To the extent that caballeity sits in the Sosein, the ancestors of the horse and the horses must previously pop up in the Dasein. According to Whitehead's vision, only geometrical forms and colours are "eternal objects". Then, the Zeitsein may be defined as the union of the Dasein and of the quiddities which, in the Sosein, are derived from the evolution at work

10 Deleuze has understood this point well. Barot has given a good account of it in his book on Lautman (Barot 2009), discussed in the symposium on Lautman (Marquis 2010). For more on the topic we must refer to our Cavaillès et Lautman, again in our scriptorium. 
in the Dasein. The Zeitsein requires its Übersistlich Darstellung in the form of Figure 1, p. 341.

This representation is a doubled cone with its upper sheet and its lower sheet, separated by a plane. The lower sheet represents time; the upper sheet with the plane represents temporality. At the top of temporality, on the empyrean of metaphysics, we find the Prototime: in order to represent it we must imagine a compass rotating in the drawing of a circle.

The center of the circle, which is marked by the puncture of the compass, represents the protopresent. The radius of the circle, measured by the opening of the compass, represents the protopast. The compass' rotation represents the protofuture. The three parts of proto-time are divided into two subsets: the protopresent and the protopast are united in the happened (advenu), while the future is à venir.

In this construction, we find a first contingency: the circle can be traced either dextrogyre, in the sense of the hands on a watch, or levogyre, in the sense of the trigonometric circle. This is only a binary contingency: the two possibilities correspond to the two tickings of the prototime-clock: if the prototime turns dextrogyre, the ticking is tick-tack; if it turns levogyre, the ticking is tack-tick.

Now, the prototime is taken in a "bushing" operation $b$. We can have an intuitive idea of its effect only by analogy. We can imagine prototime by comparing it with an elementary particle that has to go through a Young split: before it crosses it, the path of the particle is straight; when it passes through the Young split, its localisation is determined.

Yet, we shall suppose that, because of this localisation, the velocity-vector of the particle (with its three dimensions, and so with its direction too) is underdetermined. Each state of the particle, the one before and the one after the Young split, corresponds to an effect of the bushing $b$. The first one is a linearisation of what has happened: the protopast is mapped onto an actualised part of the protofuture, so that the protopresent gets its chronological standard position: being after the protopast. The second effect is a ramification of the future in a fan of "future contingents".

The result of these two bushing operations on prototime is what I propose to call Protoduration:

$$
b(\text { prototime })=\text { protoduration }
$$

From this hypostasis forth, one can conceive the genesis of the Zeitsein exploiting the affinities between the works of three philosophers: Elisabeth Anscombe, 


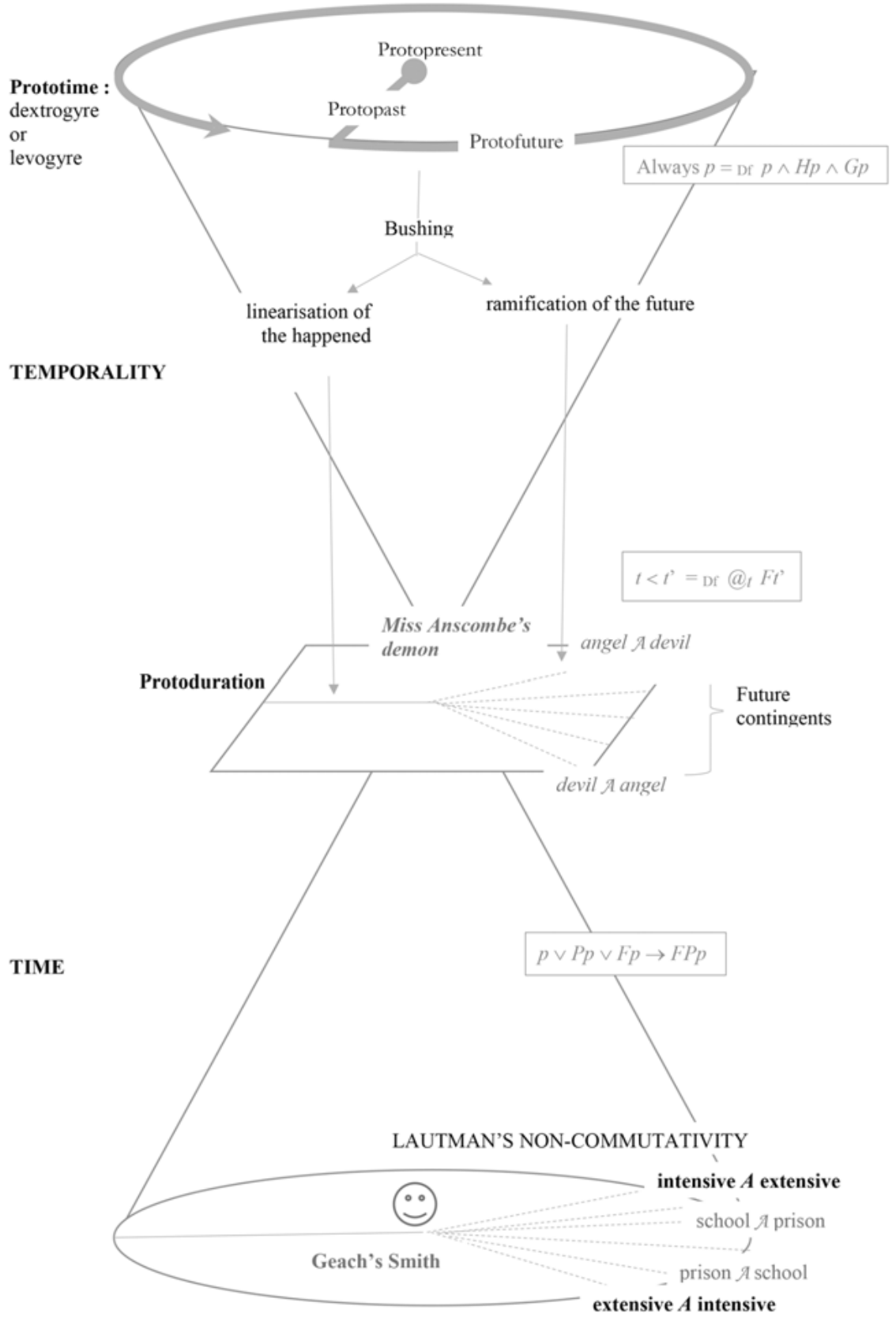

Fig. 1: Zeitsein 
Peter Geach and Arthur Prior, ${ }^{11}$ remembering that physics also has its demons: Laplace's demon, with his fatal determinism and Maxwell's demon, with his charge of neguentropy. But, since physics gives rights to its demons, we can give the same rights for metaphysics' demons.

With respect to protoduration, the tutelar demon is ${ }^{12}$ Miss Anscombe's one. Her 1964's paper Before and After provides her contribution to tense logic. The title of the paper allows us to define Miss Anscombe's demon. Its essence is dipolar, that is made of two different possibilities: being an angel and then a devil; being a devil and then an angel. In symbols, $A$ stands for the Anscombe tense operator "and after", so that the two main possibilities for her demon are:

$$
\text { angel } A \text { devil }
$$

("he is an angel, and then he is a devil")

$$
\text { devil } A \text { angel }
$$

("he is a devil, and then he is an angel")

Of course, these two possibilities are only two branches of a binary contingency amid the full fan of the contingents-futures opened by the protoduration. Thus, coming from Temporality, that is from Prototime and Protoduration, to Time, one has to distinguish between what is written in capitals and what is written in lower case.

In capital letters, we find the Lautman's non-commutativity (Lautman 2006, 269). And so, when Miss Anscombe's demon applies his metaphysical function to natural philosophy, the Leibnizian couple of the extensive and intensive becomes useful and relevant. The binary contingency will in fact take precisely the form of the two above mentioned natural possibilities:

$$
\begin{gathered}
\text { intensive } A \text { extensive } \\
\text { or } \\
\text { extensive } A \text { intensive }
\end{gathered}
$$

\footnotetext{
11 For the relationship between Anscombe and Prior, see Gardies 1975, 120. It is in a letter to Prior that P.T. Geach defined the Transworlds Airlines TWA of his relation of accessibility between possible worlds in the same way as Prior did in 1962.

12 Anscombe was already married to Geach when my friend Georges Kalinowski met her at the Manchester conclave (closed colloqium) where Arthur Prior gathered together the few pioneers of deontic logic; but, as he told me later, he learned on this occasion that, in academic circles, G.E.M. Anscombe must only be named "Miss Anscombe". And it is only under this name that she has a demon.
} 
Lautman asks to himself: is it possible to describe, in the womb of mathematics, a structure which would be like a first drawing of the temporal form able to qualify the sensible phenomena? (Lautman 2006, 277). Such a structure may be named mathematical prototemporality. Yet, our thesis is that there is also a logical prototemporality, and that logical prototemporality is the core of tense logic.

In lower case we register the fact that Elisabeth Anscombe married Peter Geach. And P.T. Geach tells us that: "Smith committed seven burglaries, then a murder and then he was hanged" (Geach 1957, 71). But in the Zeitsein Geach's Smith becomes a concrete hypostasis of the two tickings in the prototimeclock. In miss Anscombe's Begriffsschrift:

school $A$ prison

("he was at school, and then in prison")

prison $A$ school

("he was in prison, and then at school")

Now, our Zeitsein is displayed with all its hypostasises. Therefore, we can insert on its scale, each one in its proper place, the main laws of tense logic, also underlining the paradigmatic value that Prior attributed to them. ${ }^{13}$ At the top, that is on the level of Prototime, we find the definition of the modality Always given by Prior. It is not defined by an instants-quantification ("Always $p$ " = for all instants $t$ it is true at $t$ that $p$ ) but as a conjunction of temporal modalities:

\section{Always $p={ }_{\text {Df }} p \wedge H p \wedge G p$}

(“Always $p$ means by definition that $p$ and auparavant $p$ and dorénavant $p$ ”)

At the level of Protoduration Prior gives the following definition:

$$
t<t^{\prime}={ }_{\text {Df }} @_{t} F t^{\prime}
$$

" 't is before $\mathrm{t}$ " means by definition that at $\mathrm{t}$ it is future that $\mathrm{t}$ "”

Here, we see that, on the Prior palindrome, the Carnapian order between explanandum and explanans is inverted: now, the explanandum is "before", i.e., in McTaggart's terms, a B relation of the B-series; while the explanans is future, i.e., an A attribute of the A series. The latter has become a tensed modality.

At the level of Time, we find Findlay's law: the emblematic law of temporal logic which is also the first from an historical point of view. It was enunciated by

13 For a detailed exposition and explanation of this point, see Dumoncel (2018). 
J.N. Findlay in a footnote of his paper on time (Findlay 1941). And, when Prior read it, he found the impetus to investigate both temporal and tense logic. Here is Prior's formulation of Findlay's law:

$$
p \vee P p \vee F p \rightarrow F P p
$$

("If $p$ or it is past that $p$ or it is future that $p$, then it is future that it is past that p")

\section{Comparative Conclusion}

Faced with the question "What is time?", the Zeitsein thesis needs to be specified in the light of both Elie During's and Etienne Klein's papers. Elie During has enunciated a new Tertium non datur: "There is no third time" between natural time and psychological time. But, in spite of the title of the present paper, the Zeitsein thesis is compatible with During's tertium non datur.

Yet, the thesis of During seems to entail a plain answer to Etienne Klein's question: "Who is entitled to talk about time?" If there is no third time in addition to physical and psychological time, then the answer to the question is that nobody is entitled to talk about time, except for physicists such as Julian Barbour and psychologists such as Marc Wittmann.

However, we may sustain a more balanced conception. This is because, in During's terms, there is a "'natural philosophy' stemming from contemporary physics". "Natural philosophy" is a sort of constant in the development of physics from Newton to Louis De Broglie and Albert Lautman. In the Lautman scale, as we have seen, natural philosophy finds its place, as a halfway house between mathematics and physics. Moreover, when Lautman took into account von Neumann's algebra, he recognized that the mathematical stratum of his Platonic scale is a logico-mathematical edifice. From Klein's viewpoint, the logical layer included in the logico-mathematical edifice defines exactly the place of tense logic.

Within temporal logic, tense logic runs the risk of being reduced to the logic of our phenomenal time. But this is a misunderstanding. The first mathematization of modal logic coincides, in the work of Arthur Prior, with the birth of temporal logic as a paradigm for modal logic and, in this mathematization, the frame represents the ontology of the modal model. Besides, since temporal logic is a kind of modal logic, the contribution of logic in answering the question "What is time" primarily concerns the part of temporal logic where the modal involvement (in Quine's sense) reaches its maximum point: tense logic. 
Thus, if time is indisputably a feature of nature, the word becoming, as C.D. Broad remarked, reminds us that Time is primarily a feature of Being. And this is what the concept of Zeitsein shows.

\section{References}

Anscombe, Elisabeth (1964), “Before and After”, in: The Philosophical Review 73 (1), 3-24. Barot, Emmanuel (2009), Lautman, Paris.

Blackburn, Patrick/de Rijke, Maarten/Venema, Yde (2001), Modal Logic, Cambridge.

Blackburn, Patrick (2006), “Arthur Prior and Hybrid Logic”, in: Synthese 150 (3), 329-372.

Copeland, Jack B. (2002), "The Genesis of Possible Worlds Semantics”, in: Journal of Philosophical Logic 31 (2), 99-137.

Dumoncel, Jean-Claude (2008), "Review of Lautman 2006", in: History and Philosophy of Logic 29, 2, 199-205.

Dumoncel, Jean-Claude (2018), “Les degrés de la modalité selon Quine puis Prior”, in: Almukhatabat 27, 43-56.

Findlay, John N. (1941), “Time: A Treatment of some Puzzles”, in: Australian Journal of Psychology and Philosophy 19 (3), 216-235.

Flew, Antony G.N. (1951), Logic and Language, Oxford.

Gardies, Jean-Louis (1974), “Un logicien déontique avant la lettre : Gottfried Wilhelm Leibniz", in : Archiv für Rechts- und Sozialphilosophie 60 (2), 79-112.

Gardies, Jean-Louis (1975), La Logique du Temps, Paris.

Gabbay, Dov M./Woods, John/Kanamori, Akihiro (eds.) (2005), Handbook of the History of Logic, vol. 6, Amsterdam.

Geach, Peter T. (1957), Mental acts, London.

Goldblatt, Robert (2005), "Mathematical Modal Logic: A View of its Evolution”, in: Journal of Applied Logic 1(5), 1-97.

Gueroult, Martial (1934), Leibniz. Dynamique et Métaphysique, Paris.

Kalinowski, Georges (1985), Sémiotique et Philosophie, Paris-Amsterdam.

Kripke, Saul A. (1963), "Semantical Considerations in Modal Logic", in: Acta Philosophical Fennica 16, 83-94.

Lautman, Albert (2006), Les mathématiques, les idées et le réel physique, Paris.

Leibniz, G.W. (1903), Opuscules et fragments inédits, Paris.

Lewis, Clarence I./Langford, Cooper H. (1932), Symbolic Logic, New York.

Linsky, Leonard (ed.) (1971), Reference and Modality, Oxford.

Marquis, Jean-Pierre (ed.) (2010), Albert Lautman, philosophe des mathématiques, Philosophiques, 37 (1).

McTaggart, James Ellis (1908), “The Unreality of Time”, in: Mind 17 (4), 457-474.

Prior, Arthur N. (1955), “Diodorean modalities”, in: The Philosophical Quarterly 5, 205-213.

Prior, Arthur N. (1958), "The syntax of time distinctions”, in: Franciscan Studies 18 (2), 105-120.

Prior, Arthur N. (1962), "Possible worlds", in: The Philosophical Quaterly 12, 36-43.

Prior, Arthur N. (1967), Past, Present and Future, Oxford.

Prior, Arthur N. (1968), Papers on Time and Tense, Oxford. 
